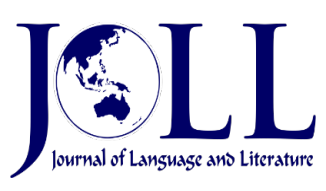

Vol. 21 No. 1, April 2021, pp. 123 - 136

DOI: 10.24071/joll.v21i1.2974

Available at https://e-journal.usd.ac.id/index.php/JOLL/index

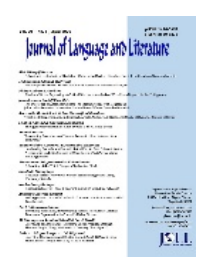

This work is licensed under a Creative Commons Attribution-ShareAlike 4.0 International License.

\title{
Critical Interpretations of Gender Stereotypes in Selected Bangladeshi TV Advertisements
}

\author{
Saheeh Shafi \\ saheehshafi@gmail.com \\ Department of English, University of Dhaka, BANGLADESH
}

\begin{abstract}
This paper aims at a precise critical interpretation of gender roles portrayed in the three selected TV advertisements shown in Bangladesh. The analysis begins with the theoretical framework of gender roles analysis here in this paper: Goffman's Gender Stereotypes Hypothesis which is used to identify and analyse the thematic features present in the ads. After critically examining the hypothesis, Kress and Van Leeuwen's Systemic Functional Analysis framework is used to analyse the semiotic feature to interpret the signs and symbols. After that, Fairclough's stylistic analysis of Discourse Analysis is used to find out these features in the advertisements to search the cultural, political implications. Lastly, the paper uses Pope's The Rape of the Lock and its Cultural-Ecofeminist Analysis of Francois d'Eaubonne to connect with the above-mentioned frameworks from a contextual point of view to form the "Multi-Disciplinary Framework" to predict the future progression of the gender representations and their implications in the coming years. Results show that despite the presence of gender stereotypes, the changes in gender roles both in houses and workplaces, women empowerment, more female entrepreneurs in the working forces will bring out about a change in the minds of people about the stereotypes and make a more women-inclusive and women-friendly environment in Bangladesh.
\end{abstract}

Article

information

Keywords: gender stereotypes; systemic functional framework; discourse analysis; cultural ecofeminism; multi-disciplinary framework

\section{Introduction}

"Advertising is our environment. We swim in it as fish swim in the water. We cannot escape it...advertising messages are inside our intimate relationships, our homes, our hearts, our heads," says Kilbourne (1999) which conforms with how advertisements 'frame' specific forms of perceptions and understanding in our mind (Gamson et al., 1992). In our day-to-day life, we find normally man in "manly" activities and woman in "womanly" activities which are also reflected in TV Advertisements. This type of 
representation of gender is called "stereotypical". The ways in which the gender representations are portrayed in the advertisements have a direct connection with the social, political, and cultural associations with gender stereotypes in different levels including thematic, semiotic, and stylistic levels. Bell and Milic (2002) had combined content analysis with semiotic analysis in Australian magazines to show gender stereotypes and their implications which will be used in the Bangladeshi context to examine whether these frameworks comply with advertisements shown in the country.

In this paper, the presentations and implications of Gender Stereotypes portrayed in three selected TV advertisements shown in Bangladesh will be critically examined in terms of Goffman's Hypothesis of stereotypical representations of gender roles which combine content-based or thematic analysis and semiotic analysis of Kress and Van Leeuwen under Systemic Functional Analysis Framework and Fairclough's Stylistic Discourse Analysis will be used to form an umbrella term "Multi-Disciplinary Framework" to study the Cultural Ecofeminism to gender roles to show the identify the representations of gender stereotypes, the reasons behind the advertising agencies to portray women as stereotypical and also to predict the gender portrayal trajectories into the future in Bangladesh. This study gives an insight into the underlying reasons for gender stereotypes and their implications in terms of their future projections which gives the researchers a further interpretation of gender stereotypes in the Bangladeshi context which is very rarely studies to date. So, choosing representative advertisements of women's beauty, power and carrier will be very essential to justify theories into practical fields. Thus this paper ads will add value to the existing body of research on gender studies.

One of the earliest known research conducted on Gender Stereotypes (Rozenkrantz et al., 1968) critically evaluates the relationship between the self-concept of people and their "differentially valued sex roles". The research group found that both male and female participants agreed in terms of their valuation of Stereotypically Masculine characteristics more than feminine ones.

Goffman's (1979) work on Gender Stereotypes and their implications are one of the major works done in the latter half of the $20^{\text {th }}$ century. Till then only a handful of researchers had joined the quest to find out more about how women and men are portrayed. His article, Gender Advertisements of 1979 deals with it from the viewpoint of how society wants us to see gender roles in Advertisements rather on what actual roles are being played in real life.

Bell and Milic (2002) later on used the Framework of Systemic Functional Analysis with Semiotic Analysis in 827 advertisements shown in Australia to revisit the Gender Stereotypes Hypothesis of Goffman to check whether these stereotypes are reinforced or not. They find that though there has been the presence of socially constructed stereotypes in TV Advertisements, there are many instances of progression towards the portrayal of women in more professional, responsible, selfsufficient roles and men in more supportive roles in women empowerment.

Ann and Kim (2007) used Hofstede's Masculinity Index (MAS) in 300 Korean Advertisements which show the Gender Stereotypes such as women portrayed more in beauty product-oriented ads, ads where the setting is home, and in "recreational" roles which are according to the requirements of the advertising agencies. This is a way of analysing the gender stereotypes and their implications from a quantitative assessment. According to them, their research will help the advertising agencies to locate their target customers' needs by using the MAS Index which in most cases comply with the existing stereotypes in gender role portrayals.

The recent trends of Gender Stereotypes in TV Advertisements are found in the research conducted by Matthes et al. (2016) in accessing 1755 advertisements in 13 Asian, American and European countries where they concluded saying that the gender of primary character or characters, voice-overs, age, the product types, setting and working roles are the factors they used to examine whether the 
gender quality conditions of a country influence the gender roles portrayals shown in TV Advertisements or not. They concluded that although there is the presence of Gender Stereotypes all over the globe, the recent trends tend to be more women inclusive compared to the last half of the $20^{\text {th }}$-century portrayals by Goffman.

To determine and signify "Gender Stereotypes", different methodologies like thematic, stylistic, semiotic analysis have been used separately for example; in Dines (1995) in which only gender and culture were addressed. Goffman (1969) used only Gender Stereotypes Hypothesis, Kress and Van Leeuwen's (1996) Systemic Functional Framework, and Fairclough's (2003) Discourse Analysis separately to examine gender stereotypes and that is why these studies were incomplete in terms of providing a comprehensive understanding of gender stereotypes. To add to this, Bell and Milic (2002), Anstey and Kim (2007) used a systemic functional framework and Hofstede's MAS Index only. Moreover, communication and media strategies of audio-visual discourse analysis are hardly present in Kellner's (1995) work in media and culture. The existing researches dealt with gender stereotypes mostly in European, American contexts. Even though Matthes et.al, (2016) examined stereotypes in the Asian context, the Bangladeshi context is not examined at all. But this Paper will provide the readers with a holistic interpretation of Gender Stereotypes and their implications in the Bangladeshi context by connecting the above-mentioned theoretical frameworks with the methods mentioned below.

Therefore, by combining InterDisciplinary Analysis of Gender Stereotypes using Goffman's (1979) Gender Stereotypes Hypothesis, Kress and Van Leeuwen's(1996) Systemic Functional Analysis, Fairclough's (2003) Discourse Analysis, Hofstede's MAS Index Analysis Framework along with a Literary contextualization using Pope's The Rape of The Lock in terms of a Cultural Ecofeminist viewpoint, a New Multidisciplinary Analysis Framework is formed to examine from the thematic, semiotic, stylistic and literary point of view.
The research question of the paper is that it deals with the main research question regarding critical interpretations of gender stereotypes (How?, Why? And Now What?) divided into three sub-questions into three aspects :(a) Gender Representations, (b) Implications of Gender Stereotypes, (c) Future Trajectories of Gender Stereotypes in the three selected TV advertisements in Bangladesh.

(a) Gender Representations (How?): How are gender stereotypes portrayed in the three selected TV Advertisements shown in Bangladesh?

(b) Implications of existing Gender Stereotypes (Why?): Why (underlying reasons) are gender stereotypes portrayed in these ways?

(c) Future Trajectories of Gender Stereotypes (Now What?): Are the stereotypes reinforced or there is any wind of change regarding stereotypes in future TV ads?

\section{Methodology}

This paper will go through an extensive interpretation of gender stereotypes by combining the theoretical frameworks with the practical analysis methods on selected TV Advertisements shown in Bangladesh in various settings by three main methods of content analysis of the "Multi-Disciplinary Framework" are given as follows.

The Thematic Analysis will be done for Goffman's(1979) Gender Stereotypes Hypothesis to determine whether the Gender Stereotypes do exist or not and if they do, to what extent these impact social, political, cultural, economic, and psychological aspects. The semiotic analysis will be critically interpreted by the Systemic Functional Framework of Kress and Van Leeuwen (1996) to examine extensively the semiotic features present in the ads to understand and justify the claims made by Goffman from the symbolic analysis.

Alongside thematic and semiotic analysis, the third dimension of Stylistic Analysis is used to examine further deep into the roots of Gender Stereotypes using Fairclough's Discourse Analysis which is explained nicely by 
Prasad (2016). As the Advertising Agencies mainly use conversations of the various participants in their advertisements, it is very crucial to study these conversations from a Critical Discourse Analytical point of view.

The overall analysis is also based on (a) Qualitative \& (b) Quantitative Analysis of examining Gender Stereotypes. Qualitative Analysis using mainly Goffman's Gender Stereotypes Hypothesis will be used to find out the underlying themes present in these ads for interpretations of gender stereotypes. Quantitative Analysis using mainly Hofstede's (2001) MAS Index to do factor analysis which will combine the theoretical frameworks based analysis with the practical on-field analysis with data collected from the three representative Advertisements. Qualitative Analysis is used to explore the sense of the Exotic in the Ads where Freud's Dream Work and the Psychological principles will be used to Psychoanalyze the minds of the participants of the Advertising, the owners of the Advertising Agencies and their potential plans or strategies, the viewers' mind as well. The Patriarchal society and the oppression of women by it are explored in terms of cultural ecofeminism which deals with the oppression against women and nature. Both Qualitative and Quantitative Analysis to give an extra contextual advantage there are Literacy Texts like The Rape of The Lock of Alexander Pope and alongside their theories complying with the current contextual scenarios.

\section{Data Collection}

The rationale for choosing the above mentioned theoretical frameworks and methods: Each of the Frameworks have been classified into multiple subframes with which newer spectacles will be re-discovered here in Women and Gender Studies. These multidisciplinary frameworks with multiple subframes are used to provide a broader spectrum to view women and gender from the best possible viewpoints by contextualizing in different real-life scenarios. By justifying gender roles, attitudes towards changes in role-plays of women, future trajectories will eventually be developed by the MultiDisciplinary Framework to interpret specific propositions.
The rationale for choosing the three advertisements: Pears Soap Ad, Bangladesh Army Ad, and Brac Ad are carefully chosen by the author from TV advertisements shown on prime broadcasting time in Bangladesh. These ads are representative of three important factors beauty, power, and carrier of women predict gender stereotypes respectively. Each of the advertisements was chosen as representatives of the above-mentioned advertising categories. The language of Bangladesh Army Ad and Brac Ad is Bangla while Pears Ad is in Hindi. When quoted from these three ads, transliteration is used alongside the meaning in English to maintain both contextual integrity and clarity of meaning. The words, phrases, and sentences used in these advertisements are collected by writing these down by the respective author while the ads were running on the TV screen.

Future trajectories of gender stereotypes: This study will also try to find out about the future trajectories of Gender Stereotypes by combining these above-mentioned frameworks with practical fields of analysis. Finally, the paper will review the abovementioned strategies to examine Gender Stereotypes whether these promote or demoralize women, and will comment on the findings using the above-mentioned Frameworks to predict their future trajectories and their impact on women folk. The three Ads show a gradual transition from a more radical point of view towards women to a more liberal point of view. The Ads also serve the purpose of Gender Roles presentations as each shows women in different familial, social, and national roles played by them.

\section{The Three Selected TV Advertisements and their dominant themes}

\section{Beauty Soap "Pears" Advertisement (2018) on Women's Beauty}

In this advertisement for Pears Golden Glow Soap, the main character is a young woman who is also the mother of a little school girl. The proceedings start with the little girl in her school uniform closing her eyes when she hears that her schoolmates are coming. She 
opens the door then also asks them to close their eyes. They are shown equipped with musical instruments. After that, she goes into her house and askes her mother to come with her to the yard. Her mother asks her what is the matter.

The little girl replies that they have a music competition and her mother's face is lucky for them and she smiles with a glow. In the meantime, the background music "Teri ek jhalak dikh jaye to din ban jaye, din ban jaye" is playing in Hindi, an Indian Subcontinental Language and the meaning in English is that if a little glimpse of her is seen, the day becomes a success. Here, only physical beauty is considered to be the reason for the little girl's feeling lucky, not her mother's musical talent or blessings. Blessing in conventional terms still makes more sense than beauty to be felt lucky about. It is a fantasy world created around the little girl in which she will follow her mother to be another "beauty icon" herself.

\section{2. "BRAC", an NGO Advertisement (2017) on Women's Empowerment}

This heart touching advertisement shows that how vulnerable women are struggling in getting their rights. The story begins with the death of the father of a young girl. When her mother claims to her Bother-in-Law about her husband's piece of land, she hears from him that he has lost his brother and she has come to ask for lands! He gives her a packet of taka and says that her daughter is fatherless and so to take care of her. Then the woman leaves her house with her daughter and makes a train journey to Dhaka. That night while her daughter was reading about Bangladesh and its land areas, she requests her mother to read that part and her mother read, "Bangladesh is our motherland. Its land area is 1,47,570 square kilometres. Then she asks her if Bangladesh's land area is $1,47,570$ square kilometres and where is their land? Her mother is seen sewing to earn their livelihood. According to a report (International Land Coalition, 2014) spoken by the male voiceover, women possess less than $4 \%$ of Bangladeshi land which shows that still how vulnerable women are in terms of land possession.
The message of the advertising is that not only in words but also by changing our minds we can make women empowerment possible by restoring their rights on lands and all other assets.

\section{3. "Bangladesh Army" Advertisement (2011) on Women's Carrier}

The beginning of the Ad shows that both men and women who are young, energetic, and brave applying for the posts of Bangladesh Army. Then the rest portion of the video shows that both are taking the challenge to overcome the obstacles in hard training to fulfil their entrance into their dream profession. The male voice over is heard saying about their dedication, hard work, and passion to serve the country directly by being a Defence Officer. After completing the training, they are seen in Army uniforms which mark their bold stance in one of the toughest professions in the world.

\section{Data Analysis}

Goffman's Gender Advertisements (1979) has continued to form the theoretical basis for content analysis framework which deals with a Hypothesis of Stereotypes in representations of male and female participants in advertisements. They are portrayed repeatedly as participants of the 'Hyperritualization' of women. One of the selected advertisements, the Brac Ad shows such traits. The Pears soap ad shows some of the dimensions of 'infantilization'. 'The feminine touch' shows up in the Pears ad, where women touch and ritually caress the object, here the soap and themselves and also the mother and the female child.

The contrast can be drawn from another selected ad of Bangladesh Army where both male and female officers are seen grasping purposefully the weapons and themselves while in training. An opposing viewpoint of equality shown in BD Army Ad can be drawn here from Eagles and Sczesney's (2009) psychological research on men, women, and directors of the leading companies in Europe found that only $4 \%$ percent of the Presidents and only $10 \%$ of the Directorial Bodies of these companies are women. That survey concluded with the reasons for the stereotypical view of 
gender roles as to see men as bosses and women as subordinate stuff.

Again the 'function rank' is supported by the sewing work of women shown in Brac Ad where stereotypically 'feminine' work is associated with women. This is supported by Eagly and Steffen's (1984) experiment where the gender stereotypes are mostly reinforced by the participants of five different social groups where women are associated with communal (selfless and concerned with others) roles and men are with agentic (selfassertive and motivated to master) roles according to their hypothesized beliefs. The contrast is the BD Army ad where both male and female participate equally in a stereotypically 'masculine' military training.

The 'family' shows that the family figures tend to demonstrate a special motherdaughter (Pears and Brac Ad) bond which is emotionally close and a special father-son (Brac Ad) bond which is emotionally distant. Zotos and Grau (2016) also support the stereotypical portrayal of gender roles according to common beliefs. They pose three questions like What? (What stereotypes), Why? (the social implications of stereotypes), and Now What? (the social consequences of it). Women are presented in family-oriented and 'decorative' roles (Uray and Burnas 2003) (Pears and Brac Ad), seen as young and in housewife roles where men are portrayed as independent, authoritarian, and professional roles with little regard to age or physical appearance (Brac and Army Ad). The exception here is the BD Army ad where women are as 'masculine' as men and shown with power, carrier, and honour (Richert and carpenter, 2004).

Lastly, the 'mirror' and 'mold' debate, where the 'mirror' part supports Goffman's Hypothesis (Brac Ad) and the 'mold' part is true for Pears Ad where the cultivation theory is in action. People's perception of society is molded by media (Gerbner 1998). Human behaviours and human relationships are then termed as 'hybrid'. Contrastively the ads which follow the stereotypes, create gender identity according to the stereotyped 'masculinity' and 'femininity' (Schroeder and Zwick, 2004). People's perceptions are always changing towards women especially those who are educated and holding professional positions tend to defy the gender stereotypes hypothesis according to Eagly and Steffen (1984).

The selected Advertisements show us a gradual transition towards a more womenfriendly environment in Bangladesh from a more radical point of view towards women. Identify formation for women has been a significant scenario to make a bold stand and take advantage of the opportunities that come into their way to be more professional, more powerful, and more boldly beautiful. The point of raising consciousness about women's rights has been one of the most talked-about topics of women. These advertisements will surely boost their morale for their future endeavours. The problems that they face like not having their rights on land will be eradicated only if they are educated and aware of their rights and thus empowered.

Overt beautification, a trap of the advertising agencies termed as "commercial reality" by Goffman (1979) is used to create a perfect realization of one's dreams. The attitudes of children towards the beauty of women is also a crucial theme that deals with the formation of a "molded" psychology for young children towards unconsciously "objectifying" themselves and making them more a "wooden doll" rather than the real-life women with consciousness about their physical and psychological beauties which they nurture not in front of the dressing tables but their school of mind as well.

The good thing is that the trend towards intellectuals nurturing is increasing among women which can be traced by looking into the ever-growing number of ads showing women's empowerment not only with beauty but also with their knowledge and skills. It means a lot to a young girl watching TV with her family where other girls of her age are shown successfully by dint of their extremely hard work and merit earned by their dedication towards their respective fields. The advertisements are still the mirrors of the society where the trend towards becoming intellectual women for girls is increasing which is shown more and more in these Ads. Bangladesh has become less MAS-centric than 
before and also a more GDI or Gender Development Index score holder which is given by United Nations (UN) which is visible in the ads showing women empowerment and carrier consciousness.

\section{Systemic Functional Framework of Kress and Van Leeuwen: Critically Interpreting Semiotic Analysis}

"Semiotic categories" depicted in Kress and Van Leeuwen's (1996) Reading Images are used to analyse the gender stereotypes in advertisements. Under the Systemic Functional Analysis Framework, according to Anstey and Bull (2018), a semiotic system is classified into five categories; such aslinguistic, visual, audio, gestures, spatial. Hofstede's (2001) Masculinity Index (MAS) is an indicator of gender stereotypes in a society which deals with different variables like the main character, age, gender, settings, women's representations as caregivers. This Index divides the countries into two categories such as; 'masculine' countries with a high MAS index and 'feminine' countries with a low MAS index. The high MAS indexed countries portray women as subordinate to men, mostly shown as holding household roles and hardly shown as professionals.

They are also shown as caregivers and associated with the "other" and the "exotic" which is an important part of a psychological study of minds of people which associate women with "colonies" "the good old days," "the happy family," "fun-loving youth" (Tolson, 1996) to create a pseudo-equality for women but a fantasy world of romantic dreams for men from where they get all their "needs" fulfilled. Post Structuralist and Post Modernist theories make their contributions in interpreting semiotics by treating cultural identities as "verb", not "noun" which implies that the identities of women are evolving with the passage of time and will go towards a more comprehensive way for them. The ritualization of subordination as a stereotype for women shows them in inferior positions as in Brac Ad where the woman becomes landless after her husband's death.

They are shown in inferior poses, for example in Brac Ad where the woman is humbly asking for the land-claim of her husband in submissive postures and gestures and seen under the protection of men (the woman was under the protection of her husband and now becomes landless). Belknap and Leonard (1990) claim that women caress and men more grasp as seen in the Pears and BD Army Ad respectively. Women are portrayed as 'decorative' and 'alluring'. Women shown as infants is a semiotic device. Infantilizing women is to associate women with feeble, meek, subordinate children. On the other hand, whenever women are shown in 'masculine' positions, they are depicted in 'proffering' poses for male sexual consumption (Wex 1979). At the same time, women have been subjected to association with home, pleasure, exotic, nature, and the 'colony' which connote the exploitation of the 'other' and conceal the hedonistic capitalism (Pears Ad) in Williamson's (1987) proposal.

This generation of connotative meaning is full of 'Ad Work' which is similar to Freud's 'Dream Work'. It is due to commercial and political pressure. Formal semiotic strategies are used to quench the thirst of the 'hungry' people's psychological need for fantasy. Kress and Van Leeuwen (1996) use 'Visual Semiotic Theory' to explore the connotative meanings of gender Stereotypes which are part of Hallyday and Hassan's (1985) "Systemic Functional Approach." The narrative process ('going ons') and conceptual process ('ideas') are part of the representational dimension where there are transactions and interactions with vectors (eye lines, gestures indicating a line of force). For example, in the first scenes of Ads of Brac, BD Army, and Pears where a woman is dominated by men in the Brac $\mathrm{Ad}$ whereas women pose is strong and 'focused' appearance in BD Army and Pears Ads consecutively.

The conceptual process reflects women's association with 'nonactive'/'conceptual' (beauty in Pears Ad) as carriers of symbolic (semiotic) meaning. It is as if males 'act' and females 'are'. In the interaction between participants and viewers, factors (the 'gaze' towards the camera or not, the 'distance' between them, and the 'angle' from which they are seen). The 'gaze' is more intensely portrayed in Pears and BD Army Ads where the participants create expressions of beauty, 
power, and confidence. 'Angle' is used especially for Pears Ad where the woman is seen caressing soap and herself from multiple angles to focus on her beauty.

The 'distance' is a minimum level for mother-daughter in Pears and Brac Ads and more distance between the father-son in Brac Ad. So, the first pair is more emotionally attached than the second. The 'gaze' and 'angle' are the key semiotic devices for BD Army Ad which reflect women's power, solidarity, dedication, endeavour, and hard work. On the other hand, the participants were seductively presented with the product (Pears) so that the viewers should desire them. Hall's (1969) discussion of 'proxemics', the psychology of people's use of space show intimacy, love, and attraction when it is 'intimate distance' or 'personal distance' and when it is 'social distance' or 'public distance', it shows less solidarity and more formality of relations. The mother-child and the child-child relationship in Pears and Brac Ads show the first category and the father-son and mother-uncle relationship in Brac Ad show the latter.

The 'gendered voice of advertising' shows that the male voice is associated with professional and entertaining roles while the female voice is associated with decorative roles. For example, the female voice and voiceover in Pears Ad, the male-female voices with the male voiceovers of Brac and BD Army Ads show conformity with the 'gendered' voice due to the "Stereotyped" specificity of the voices with the Ads. From a visual semiotic perspective, the falling of a dead leaf and a lonely 'Dolna' (Swing) in the background show that probably someone has died. The same predicted thing occurs and the father of the girl dies and later on the mother-daughter is ousted from their land in Brac Ad. The setting of the background of the house shows the woman's profession as a homemaker in Pears Ad and also the colour orange or golden in the dress and background match with the colour of the soap.

This colour symbolically presents the woman as seductive using the soap and also creates a hedonistic impression on the viewers. The dark colour shown in Brac Ad demonstrates the fate of the $96 \%$ of women who do not possess their land. The voice of the ad is through encouraging enough to build awareness regarding the landless women and urges for women's rights of land and property. The "money" becomes a strong symbol of envy and jealousy when the uncle of the young girl gives her mother only a handful of money and it eventually turns out to be a sign that they have to leave the land to him in Brac Ad. The background music is so 130 esmerizing and enchanting that people memorize the song and the product name at the same time subconsciously like in Pears Ad.

\section{Analysis to Uncover the Hidden Strategies by Fairclough's Discourse Analysis}

The stylistic features of language also portray Gender Stereotypes according to Prasad (2016). In Fairclough's (2003) Analysing Discourse, style is the discourse of ways of being and identity which are closely associated with the languages of the three selected TV ads that portray Gender Stereotypes. Styles are linked to identification whereas identity is an effect of discourse. PostStructuralist and Post-Modernist theories associate an identity with discourse. People are not only primary agents to be prepositioned with roles but also as social agents who do, create and change things. According to Archer (2000), creating 'selfconsciousness' is essential in forming a social identity. The Brac Ad is showing women as primary agents who are predestined to sufferings like losing their land.

Lakoff (1973) termed the word "politeness device" as part of the syntactic analysis which is used by the woman in Brac Ad to maintain the conversation with her husband's brother. Similarly, the women in BD Army Ad on the other hand are changing their lots by being flexible as social agents. Maclntyre (1984) explained the 'stock' characters which represent a culture distinctively from other cultures. Here, the woman and her daughter in Brac Ad is distinctive of "rural exploited women" and men is "the exploiter". Again in Pears Ad, the woman and her daughter are 'stock' characters of a fantasy world of the capitalist business arena where the woman is caressing the soap and the daughter feels lucky 
before going to music competition just seeing her mother's face before seeing anything else with all her mates. Features like simple syntactic structure, high rate of repetition, and direct appeal to the viewers are present in all three Ads.

All the sentences are simple, each sentence has a part that repeats in another sentence. For example, "Teri ek jhalak dikh jaye to din ban jaye, din ban jaye (II)", means "If I get to see a glimpse of your glimmering face, it makes my day a success (II)". In Brac Ad, there is the usage of simple sentences and multiple repetitions; for example: "Bangladesh is our Motherland. It's land area is $1,47,570$ Square Kilometers (2)". The little girl poses a question to her mother and the country symbolically that, in their motherland where is their land? It reflects that only less than $4 \%$ of Bangladeshi lands are owned by women and connotes the land grabbing men.

The BD Army Ad also has simple structures to convey the qualities of the Army like confidence, bravery, spirit, dream, endeavour. The Pears Ad is a descriptive, poetic, and aesthetic $\mathrm{Ad}$, the Brac $\mathrm{Ad}$ is narrative and descriptive and the BD Army Ad is descriptive and expressive. The rhyme of the background song of Pears is very soothing to the ear and intensifies the meaning of the discourse. Poetic language focuses more on the affective meaning rather than referential meaning. It uses overtly glorifying rhymes to entice the customers to use the product. The other two ads do it with their narrative and descriptive styles.

The simple structure is a part of 'loaded' language according to Bolinger. The words "jhalak" and "din ban jaye" have attention value so as the words "courage", "endeavour" and "dedication" for BD Army Ad. Use of exclamation (Wow! in Pears Ad) and question (In our motherland, where is our land, ma(mother)?" help to decipher the hidden meaning of the context which are the colonial mind and land grabbing mind of men. All the Ads have simple, familiar vocabularies. Memorability is achieved through alliteration, metrical rhyme, grammatical parallelism, lexical repetition, syntactic repetition, repetition of product names which are common in these ads. Leech's positive adjectives are present in both Pears and BD Army Ads. Words like "special", "jhalak" (flash), "100\%", "extra", "courage", "endeavour", "dream", "desire" create positive impressions on the viewers, especially the product users. Here both Qualitative and Quantitative Analyses are done to examine the Gender Stereotypes better and these will be used to further research by combining with it a literary flavour containing both thematic and contextual scenarios with practical fields of advertisings to implement those theories into practice and justify the future trajectories of gender stereotypes.

\section{Cultural Ecofeminism on Gender Stereotypes and its Implications}

\section{Literary Theories into Practice}

A cultural ecofeminist study by Mohammadi and Kalantari (2016) shows that the exploitation of women and nature in the hands of patriarchal society can be equated with two of the selected advertisements: Pears Ad and Brac Ad. The male-dominated society equates women and nature to erode them both as inactive the "other". Salma (2011) talks about the metaphor of the British Empire equated with Belinda, the main female protagonist in Alexander Pope's The Rape of the Lock. In the ad of Brac, we find that the male-dominated society grabs lands belonging to women. So, even though colonialism is eroded from the earth, the colonial mindset is still present to date which is shown in this ad. Westfall (1998) criticized Pope for not showing any progress in the plot of the storyline in The Rape of the Lock where Pope only showed female coquetry. The patriarchal domination is made trivial and less serious than what it is supposed to by Phillips (2004) Pope, Donne, Milton, Aphra Behn, Margaret Cavendish for downgrading women and earth by speakers eg. Lovers, Theologians, Colonists. For example, in Donne's Elegy XIX: To His Mistress Going to Bed, the female-beloved is treated as colonized lands by the male-lover: "Oh my America, my new found lande, /My kingdome, safeliest when with one man man'd," (27-28). Francois d'Eaubonne who coined cultural ecofeminism says that the patriarchal society defines women to preserve 
beauty and chastity and men to preserve power, authority, and earth.

Beauty is considered a virtue itself. Her physical characteristics magnify her virtuosity. "If to her share some female errors fall, look at her face,/ you will forget 'em all."(P.8) Intellectuality and other virtues are dismissed and victimization is internalized as it is only women's duty to protect their beauty and chastity. It is similar to Brac Ad where a legal claim of a woman was dismissed and internalized and she has not protested and taken any action. "She who scorns must die a maid!", "Beware of all, but most beware of men", "Weights men's wits against lady's hair, Belinda is marginalized even though she outwitted the Baron in the game of Ombre and beauty(women) loses to wit(men) as if each of them is associated with exclusively to either male or female. It is similar to recurrent background music "Teri ek jhalak dikh jaye to, din ban jaye" where beauty is exclusively associated with women. Freud's psychoanalytical theory conforms with Illouz's (1996) observation of "fantasy generated emotional experience" for which the Baron wants to "ravish" Belinda's hair which is still prevalent in the Bangladeshi context as well.

\section{Results and Discussion}

Both the Representations and Implications of Gender Stereotypes in Bangladesh according to the newly developed Multi-Disciplinary Framework by the author mostly conform with the combined findings.

Table 1: Results of Existing Researches on the selected TV Advertisements

\begin{tabular}{|c|c|c|c|}
\hline Name/s and Year & Pears Ad & Brac Ad & Army Ad \\
\hline Bell \& Milic (2002) & Stereo-typical & Both Stereo-typical and Not & Not Stereo-typical \\
\hline $\begin{array}{c}\text { Uray and Burnaz } \\
(2003)\end{array}$ & Stereo-typical & Both Stereo-typical and Not & Not Stereo-typical \\
\hline $\begin{array}{c}\text { Reichert and } \\
\text { Carpenter (2004) }\end{array}$ & Stereo-typical & Both Stereo-typical and Not & Not Stereo-typical \\
\hline $\begin{array}{c}\text { Zotos and Grau } \\
(2016)\end{array}$ & Stereo-typical & Both Stereo-typical and Not & Not Stereo-typical \\
\hline
\end{tabular}

Table 2. Results of Theoretical Frameworks on the selected TV Advertisements

\begin{tabular}{|c|c|c|c|}
\hline Name/s with Year & Pears Ad & Brac Ad & BD Army Ad \\
\hline Goffman (1979) & Stereo-typical & Both Stereo-typical and Not & Not stereo-typical \\
\hline $\begin{array}{c}\text { Kress and Van } \\
\text { Leeuwen (1996) }\end{array}$ & Stereo-typical & Both Stereo-typical and Not & Not stereo-typical \\
\hline $\begin{array}{c}\text { Fairclough } \\
(2003)\end{array}$ & Stereo-typical & Both Stereo-typical and Not & Not stereo-typical \\
\hline
\end{tabular}

\section{Goffman's (1979) Gender Stereotypes Hypothesis}

By examining the most dominant themes, Goffman's Gender Stereotypes Hypothesis is justified in terms of thematic analysis by identifying the main gender stereotypes criteria including beauty, empowerment of women in Pears Ad and Brac Ad but contrasts with BD Army Ad where women are associated with more "masculine" roles which means wind of change is starting to blow to show that women are treated as equal by their male counterparts in BD Army. 


\section{Kress and Van Leeuwen's (1996) Systemic Functional Framework}

The Multi-Disciplinary Framework used Systemic Functional Analysis to justify the thematic analysis combine with practical analysis. The semiotic features also conform with the Stereotypes of seeing women as objects, at home in recreational roles and gives us an insight into the insiders' mind of the advertising agencies and also the "imperial" mind of the male-dominated society which eventually turn into an "objectifying" attitude towards women irrespective of all classes.

Here Freud's Dream Work has worked in favour of the analysis Framework to support the claims made according to the semiotic analysis.

\section{Fairclough's (2003) Stylistic Analysis}

Fairclough's Discourse Analysis deals with the stylistic aspects of gender stereotypes and their implications by examining the discourse in the context of Gender Roles portrayals in Bangladesh. The stylistic analysis in terms of phonetics, phonology, morphology, syntax, and semantics as a part of discourse analysis makes it evident to justify gender stereotypes and also points out future trajectories of gender stereotypes using the same means which are used to examine gender stereotypes.

\section{Literary Interpretation}

The literary viewpoint also makes the strong claim of Gender Stereotypes portrayal in Bangladesh in the $21^{\text {st }}$ century even stronger and gives an insight into the oppression of women and nature by men. Using Cultural Ecofeminism as a tool to find out the troublesome experiences of women even in the $21^{\text {st }}$ century. Even though Pope's The Rape of the Lock is an $18^{\text {th }}$ Century Epic Poem but still it manages to examine gender stereotypes better because of its being universal in terms of women subjugation and oppression. This is also a most concerning finding that even in our modern times' women are maybe safe from the direct physical assault but still, they go through an inexplicable amount of mental trauma and most of them have to go through this. They are being "objectified" even though they are not aware of the "hungry mind's" psychological crimes.

\section{Implications of Stereotypes}

Blum's (2004) writing finds this Stereotypical mind which reads every category according to pre-occupied ideas:

\section{"It is false, or at least misleading, to say th at Jews are cheap, Blacks lazy, Asians good at math, women emotional, and so on,"}

The good thing is that the change for a more women-friendly job environment is reflected in BD Army Ad. Due to the development of more women inclusive education system, job sectors as well as job environment, the advertising agencies are starting to show women in more positive and important roles and also a partner of men in the development of a Developed Bangladesh. As more and more women are getting quality education due to the facilities given by the Government and NGOs like Brac, women have become more self-sufficient. But overt Femvertising may put a brake on the development of women folk as these are the works of the "predatory mind". So promoting women as successful entrepreneurs in different sectors of Bangladesh will boost up other women who have the potentiality to go forward by building a positive mindset and attitude towards women by both men and women to make sure an inclusive world for women in terms of safety, respect and glory. So, the New Multi-Disciplinary Framework of Gender Stereotypes Analysis will help the researchers in this field to examine deep into the gender stereotypes and their implications.

\section{Conclusion}

The paper will end here with two contrasting propositions about predictions of Gender Stereotypes in ads shown in Bangladesh. Zotos and Tsichla (2004) say that due to the change in occupational opportunities and domestic structure, women are seen more as a professional rather than a housewife. Due to the development of new opportunities for women, they are now portrayed in more independent, professional, 
and self-sufficient roles. "Femvertising" is using Ads to celebrate women rather than objectifying them. Such an enlightened woman of Bangladesh is Prof. Niaz Zaman of the English Department, Dhaka University who says, "If there is a wall in front of me, I will scale it or bring it down". The positive impact is that boosts girls' self-esteem and breaks down gender inequality (Bahadur 2014).

But overt Femvertising without authenticity can be less effective. For example, a Lux Ad (October 5, 2020) shows that Indian Actor Saif Ali Khan overtly praising another Indian Actress Karina Kapoor Khan by comparing her "beautiful" face with the "whiteness" of the Moon but the irony is in Ad title "Lux Rose and Vitamin E" to cure skin with Vitamin. There has hardly been any dark coloured woman shown in Ad of Beauty Soap Meril (February 2020) where the dark colour is promoted and celebrated. The professional portrayal in a recent (March 2020) ad of Lux soap shows actress Mim performing an action scene with 'alluring' makeup, dark red lipstick, and stylish hair which is barely the case for our real-life action heroines for example women police or army who perform their action with bravery and intelligence rather than on 'beauty' which is used by the advertisers to allure more viewers who will mainly quench their psychological thirst of women fantasy.

Contrastively, the report of Jones (2020) where two petitions were filed against Unilever for promoting "anti-blackness sentiment" and "be light to feel beautiful" and according to the Court's verdict, it removed "fair" from "Fair and Lovely" beauty cream which is a bold step forward for reducing portrayal of the Stereotypical "Whiteness". Along with that, low MAS Index scores and high GDI Index scores, the gender roles portrayal is enduring a positive change in the Stereotypes to 'mold' new cultural identities of 'masculinity' and 'femininity'.

Therefore, the Gender Stereotypes shown in TV advertisements in Bangladesh complies with this Multi-Disciplinary Framework as it shows positive future trajectories change of Gender Stereotypes in Bangladesh and will be an ideal model to follow to examine the future trajectories of gender role representations in other countries as well in future Research Proposals.

\section{References}

Ahmed, T. (2011, July 12). Bangladesh Army TV Commercial [Full-Length Version] [Video File]. Retrieved from https://youtu.be/3BJsF7pbXEY

An, D., and Kim, S. (2007). Relating Hofstede's masculinity dimension to gender role portrayals in advertising. International Marketing Review, 24(2),181-207.

Anstey, M. and Bull, G. (2018). Foundations of Multi-literacies: Reading, writing and talking in the $21^{\text {st }}$ century. London: Routledge.

Arc Archer, M. (2002). Being Human: The Problem of Agency. Cambridge: Cambridge University Press.

Bahadur, N. (2014). Femvertising ads are empowering women- and making money for brands. Huffington Post, (October 3), http://huffingtonpost/2014/10/02/fem vertising-advertising empowering $\mathrm{n}$ 53211000.html.

Belknap, P. and Leonard, W. M. (1991). 'A Conceptual Replication and Extension of Erving Goffman's Study of Gender Advertisements. Sex Roles, 25(314), 10318.

Blum, L. (2004). Stereotypes and stereotyping, a moral analysis. Philosophy Papers, 33(3), 251-289.

BRAC. (2017, July 28). বাংলাদেশ কি আসলেই আমাদের মাছভূমি? [Video File]. Retrieved from: https://youtu.be/1hDeEj7D0T4

Bell, P. and Milic, M. (2002). Goffman's Gender Stereotypes revisited: Combining Content analysis with semiotic analysis, London: Sage Publications, $l(2), 203-222$. 
Bolinger, D. (1980). Language: The Loaded Weapon. London: Longman.

Donne, J. (1971). Poetical Works. Ed. Herbert J. C. Grierson. Oxford: Oxford UP.

Eagly, A. H., and Sczesny, S. (2009). "Stereotypes about women, men, and leaders: have times changed?," in The Glass Ceiling in the 21st century: Understanding Barriers to Gender Equality, Washington, DC: American Psychological Association, 21-47.

Fairclough, N. (2003). Analysing Discourse: Textual Analysis for Social Research. London: Routledge.

Freud, S and Brill, A. A. (1915). The Interpretation of Dreams. Rev. ed. London: New York. G. Allen and Unwin Ltd.

Gamson, W., Croteau, D., Hoynes, W., and Sasson, T. (1992). Media images and the social construction of reality. Annual Review of Sociology, 18, 373-393.

Gerbner, G. (1998). Cultivation analysis: An overview. Mass Communication and Society 1, 175-94.

Goffman, E. (1979). Gender Advertisements. Cambridge, MA: Harvard University Press.

Grau, S. L., and Zotos, Y. C (2016). Gender stereotypes in advertising: a review of current research. International Journal of Advertising, 35(5), 761-770.

Hall, E.T. (1969). The Hidden Dimension. Garden City, N.Y: Anchor Books.

Hallyday, M.A.K. and Hasan, R. (1985). Language, Context, and Text: Aspects of Language in a Socio-Semiotic Perspective. Deakin: Deakin University Press.

Herrmann and Abigail J. Stewart (eds). Theorizing Feminism: Parallel Trends in the Humanities and Social Sciences. Boulder, CO: Westview Press.

Hofstede, G. (2001). Culture's Consequences: comparing values, behaviours, institutions, and organizations across nations (2nd ed.). Thousand Oaks, CA: SAGE Publications.

Illouz, E. (1996). Consuming the romantic utopia: Love and the cultural contradictions of capitalism. Berkeley, CA: University of California Press.

Jones, L. (2020 June 25). Unilever renames Fair and Lovely skin cream after backlash. BBC News.

https://www.bbc.com/news/business$\underline{53178088}$

Kellner, D. (1995). Cultural studies, multiculturalism, and media culture. In G. Dines and J. Humez (Eds.), Gender, race and class in media. Thousand Oaks, CA: Sage.

Kress, G. and Van Leeuwen, T. (1996). Reading Images: The Grammar of Visual Design. London: Routledge.

Kilbourne, J. (1999). Deadly persuasion: Why women and girls must fight the addictive power of advertisements. New York, NY: The Free Press.

Lakoff, R. (1973). Language and Woman's Place. Language in Society, 2(1), 45-80.

Leech, G. (1966). English in Advertising. London: Longman.

LUX Bangladesh. (2020 October 5). Lux Rose and Vitamin E. [Video File]. Retrieved from: https://youtu.be/kjR83UBtPpI

LUX Bangladesh. (2020 March 7). Priyodorshini. Lux Boldly Beautiful. [Video File]. Retrieved from: https://youtu.be/O-zG incilo

Matthes, J., Prieler, M., and Adam, K. (2016). Gender-Roles Portrayals in TV Advertising Across The Globe. Sex Roles, 75(7-8), 314-27.

Mclntyre, A. (1984). After Virtue, Notre Dame, Indiana: University of Notre Dame. 
Meril. (2020 February 10). ফ্রেশ মানেই সুন্দর TVC 30 Sec. [Video File]. Retrieved from: https://Youtu.be/mFUhYPpVLcU

Mohammadi, N. and Kalantari, A. (2016). The Concurrence of Women and Nature in Alexander Pope's The Rape of the Lock: A Cultural-ecofeminist Reading. International Journal of Advertising.

Pears India. (2018, February 14) Pears Golden Glow [Video File]. Retrieved from https://youtu.be/A-vRCUS3MZk

Prasad, B. N. (2017). Stylistic and linguistic features of English in Advertisements. National Conference on Marketing and Sustainable Development.

Phillips, B. (2004). The rape of mother earth and seventeenth-century English poetry: An Ecofeminist Interpretation. Atlantis, 26(1), 49-60.

Pope, A. (2004). The Rape of the Lock. London: Sovereign Sanctuary Press.

Reichert, T., and Carpenter, C. (2004). An update on sex in magazine advertising: 1983-2003. Journalism and Mass Communication, 81(4), 823-37.

Saba, A. (2014 March 28). An Afternoon with a Difference. The Daily Star. Retrieved from: https://www.thedailystar.net/anafternoon-with-a-difference-17498

Salma, U. (2011). Women and the empire in Alexander Pope's The Rape of the Lock: A Reading, Transitional Literature, 4(1).

Schroeder, J.E., and Zwick, D. (2004). Mirrors of Masculinity: Representation and identity in advertising images. Consumption, Markets, and Culture, 7, 2152.

Tolson, A. (1996). Mediations: Text and discourse in media studies. London: Arnold.

Uray, N., and Burnaz, S. (2003). An analysis of the portrayal of gender roles in Turkish television advertising. Sex Roles, 48(1-2), 77-87.

Westfall, C. (1998). The negative images of women in Alexander Pope's The Rape of the Lock. Knox College Common Room: Knox College Online Journal of Literary Criticism, 2(2), 1-4Retrieved https://departmens.knox.edu/engdept/C ommonRoom/The Common Room Ho M e.html.

Wex, M. (1979). Let's Take Back our Space: 'Female' and 'Male' Body Language as a Result of Patriarchal Structures. Hamburg: Fruen-literaturverlag, Hermine Press.

Williamson, J. (1994). 'Woman Is an Island: Femininity and Colonization', in Anne C.

Zotos, Y,. and Tsichla, E. (2014). Snapshots of men and women in interaction: An Investigation of stereotypes in print advertisement relationship portrayal. Journal of Euromarketing, 23(3), 35-5. 